\title{
Espelho de príncipe: reflexões a partir do Manual de Dhuoda
}

\author{
Terezinha Oliveira \\ Ana Paula dos Santos Viana \\ Universidade Estadual de Maringá
}

\section{Resumo}

Apresentamos um estudo acerca do Manual de Dhuoda (século IX), visto por estudiosos da obra como Espelho de príncipe, um gênero literário, cuja finalidade era apresentar uma proposta de formação moral, política e religiosa para os jovens desse período. Com essa perspectiva, este estudo situa-se no campo da História da Educação Medieval, tendo como objetivo refletir acerca deste gênero literário como elemento pertinente à formação do nobre cristão. A partir desta perspectiva, tecemos reflexões ao sentido de autoridade e liderança; situaremos o contexto histórico e as formulações contidas no Manual de Dhuoda, explicitando em que medida sua proposta segue as premissas deste gênero literário.

Palavras-chave: História da Educação medieval. Dhuoda. Espelho de Príncipe. Autoridade. Líder. 


\section{Prince mirror: reflections from the Manual of Dhuoda}

\section{Abstract}

We present a study of the Dhuoda Manual (nineteenth century), seen by scholars as the work prince mirror, a literary genre whose aim was to present a proposal for a moral, political and religious to the young people of that period. With this perspective, this study lies in the field of Medieval History of Education, aiming to reflect on this literary genre as a relevant element in the formation of the Christian nobleman. From this perspective, we reflect the sense of authority and leadership; We will place the historical context and the formulations contained in Dhuoda Manual, explaining to what extent its proposal follows the premises of this literary genre.

Keywords: History of medieval education. Dhuoda. Prince mirror. Authority. Leader.

\section{Príncipe espejo: reflexiones desde Manual Dhuoda}

\section{Resumen:}

Se presenta un estudio del Manual Dhuoda (siglo IX), visto por los estudiosos como el espejo príncipe trabajo, un género literario cuyo objetivo era presentar una propuesta de moral, política y religiosa a los jóvenes de la época. Con esta perspectiva, este estudio radica en el ámbito de la Historia Medieval de Educación, con el objetivo de reflexionar sobre este género literario como un elemento relevante en la formación del noble cristiana. Desde esta perspectiva, se reflexiona el sentido de la autoridad y el liderazgo; colocaremos el contexto histórico y las formulaciones contenidas en el Manual Dhuoda, explicando en qué medida su propuesta sigue las premisas de este género literario.

Palabras clave: Historia de la educación medieval. Dhuoda. Prince espejo. Autoridad. Líder. 


\section{Miroir prince: réflexions de Dhuoda Manuel}

\section{Résumé:}

Nous présentons une étude du Dhuoda Manuel (IXe siècle), vu par les chercheurs comme le miroir des travaux de prince, un genre littéraire dont le but était de présenter une proposition pour une morale, politique et religieux pour les jeunes de cette période. Dans cette perspective, cette étude se situe dans le domaine de l'histoire médiévale de l'éducation, dans le but de réfléchir sur ce genre littéraire comme un élément pertinent dans la formation du noble chrétien. Dans cette perspective, nous réfléchissons au sens de l'autorité et de leadership; nous allons placer le contexte historique et les formulations contenues dans le manuel Dhuoda, expliquant dans quelle mesure sa proposition suit les locaux de ce genre littéraire.

Mots-clés: Histoire de l'éducation médiévale. Dhuoda. Miroir Prince. Autorité. Leader.

\section{Introdução}

A obra de Dhuoda (século IX), intitulada La Educación Cristiana de mi hijo, inserese sob o formato Espelho de Príncipe, um gênero literário que, no período medieval, era composto por reflexões de orientação moral e política. Estas reflexões, em sua maioria, estavam ligadas ao modelo cristão de virtudes. Com essa perspectiva, observamos que este estudo situa-se no campo da História da Educação Medieval, tendo como objetivo refletir acerca deste gênero literário como elemento pertinente à formação do nobre cristão, ou de um príncipe, ou seja, daquele que cuja função dirige-se à boa conduta e, por conseguinte, à governança.

A proposta deste estudo foi elaborada a partir de alguns fatores. Primeiramente, explicitamos que são reflexões realizadas no contexto de um grupo de estudos, certificado pelo CNPq e que suscitaram (e suscitam), em nós, questões e inquietações, as quais culminaram em uma pesquisa de Mestrado. A partir dos resultados das reflexões depreendidas naquele momento e em consonância com situações vivenciadas cotidianamente constituíram-se alguns motivos que ampliaram as reflexões acerca deste estudo, principiado outrora.

Vale destacar que as discussões desenvolvidas nos encontros daquele grupo de estudos são motivadas por questões contemporâneas, cujo propósito é 
pensar reflexivamente sobre a educação, ou seja, é em decorrência de nossas preocupações com o pensar e o agir, segundo nossos conhecimentos para o ato de educar as pessoas no tempo presente, que nos debruçamos sobre obras clássicas e, por conseguinte, voltamos nosso olhar ao passado.

Compreendendo que há diversas perspectivas de análise no campo da História e da História da Educação para olhar o passado, explicitamos que o campo teóricometodológico adotado é o da História Social, seguindo as premissas de longa duração. Desse modo, o objeto de estudo faz parte da totalidade representada pelos diversos aspectos que envolvem os homens. A História da Educação, por seu turno, nos permite compreender a educação como fenômeno social, fruto das relações humanas, necessárias à formação dos sujeitos para viverem em sociedade. Esses aspectos que envolvem os homens são os que permeiam as relações sociais: educacional, econômico, político, etc.

Assim, ao mencionarmos a pouco que são as questões, situações, embates observados e debatidos nos dias atuais que impulsionam nossas inquietações e, por conseguinte, resultam em nossa escrita, observamos que esses questionamentos giram em torno da responsabilidade que uma pessoa (cidadã, mãe, professora) tempara com seu próximo e, por conseguinte, sua sociedade. Como cidadãs, compreendemos que as ações convergem ou não para o bem comum, para a vida em comum de uma sociedade que vive, como outrora disse Hannah Arendt, 'em tempos sombrios ${ }^{1}$ '. Como mães, concentramos nossa atenção na e para a educação de nossos filhos e entes, como estes pensam e agem em seu cotidiano segundo sua educação. Como professoras, a apreensão reside em saber como está a qualidade da educação brasileira ${ }^{2}$, da qual fazemos parte seja como estudante de um Programa de Pós-Graduação, seja como professora, cuja função compete formação humana e intelectual, tanto dos alunos quanto de outros professores, seus pares. Desse modo, surgem alguns questionamentos: o que baliza a educação? Qual a responsabilidade que cada pessoa tem perante essa sociedade a qual pertencemos? Somos 'espelho' aos alunos, entes e pares?

As inquietações são diversas e temos consciência de que elas não estão dispostas em um plano simples de serem respondidas. Contudo, acreditamos que o leitor

1 Utilizamos a expressão 'tempos sombrios' para nos referirmos ao conturbado cenário político atual em que se encontra a sociedade brasileira. A referida expressão é oriunda de um dos títulos dos diversos livros escritos por Hannah Arendt (1906-1975), filósofa política alemã de origem judaica. A referida obra é Homens em tempos sombrios, publicado, pela primeira vez, em 1968, reúne ensaios biográficos de homens e mulheres que viveram os "tempos sombrios" da primeira metade do século XX marcados pelo afloramento de regimes totalitários como nazismo e stalinismo. Nesse sentido, ainda que aquele assunto influencie nossa busca por conhecer os "Espelhos de Príncipe", afinal, nos permite refletir sobre as orientações, princípios, formação para o ideal de um bom governante, destacamos que não adentraremos nos pormenores da atual conjuntura política no Brasil, uma vez que nos distanciaria do objetivo deste estudo.

2 O que chamamos de qualidade é a educação que propicia a pessoa uma formação ampla e capaz de tornar o sujeito uma pessoa atuante e consciente de seus papéis sociais. 
deva estar se perguntando: o que as situações, indagações aparentemente tão corriqueiras de uma pessoa (cidadã, mãe e professora) têm relação com as reflexões sobre o Espelho de príncipe enunciado no título deste estudo? Destacamos que para compreensão das circunstâncias sociais, econômicas, políticas que vivenciamos, foram e são imprescindíveis uma formação intelectual, humana, social completa , e esta formação faz parte, a nosso ver, da caminhada acadêmica pelos clássicos ${ }^{3}$. Com base nesses estudos, podemos compreender, por exemplo, que o Espelho de Príncipe, que será analisado nas páginas seguintes, só pode causar ansiedade por apreendê-lo se ele nos é 'útil', ou dito de outro modo, se o conhecimento deste conteúdo histórico nos toca como vida, do contrário ele seria apenas mais uma informação ${ }^{4}$.

Nesse sentido, do ponto de vista de estudiosos da obra de Dhuoda, seu manual insere-se sob o formato Espelhos de Príncipegênero cuja finalidade era de apresentar uma proposta de formação e de educação moral, política e religiosa para formar os jovens desse período. Contudo, a obra de Dhuoda possui uma particularidade: a autora não escreve para clérigos, laicos ou príncipes, e sim para o próprio filho, Guilherme. Nas virtudes sociais necessárias à formação de seu filho, a fidelidade ocupa espaço central. Ainda que dirija seu Manual no âmbito do sujeito singular (Guilherme), porque é um homem que deve devotar fidelidade ao rei, essas relações feudo-vassálicas só existem se pensadas coletivamente. Ou seja, os homens agem individualmente e são responsáveis por suas ações, mas este singular faz parte do todo, que é a sociedade do século IX.

Indubitavelmente, Dhuoda e seu filho viveram em uma sociedade hierarquizada, em que reconhecem na autoridade do governante (Carlos, o Calvo), de seu pai (Bernardo) e de Deus, personagens a quem eles deviam fidelidade. Assim, é legítimo que os súditos sejam fieis ao rei, que os cristãos sejam fieis a Deus e os filhos, aos pais. Do ponto de vista de Dhuoda, esta fidelidade é condição para a existência de Guilherme e para o estabelecimento da ordem na corte, no convívio em comum, ou seja, para a permanência de sua vida e para que exista o bem comum é preciso que haja fidelidade à hierarquia, respeito à autoridade ${ }^{5}$. Para explicitarmos essa ideia, teceremos algumas reflexões e aproximações acerca do sentido de autoridade e liderança antes de adentrarmos na temática do Espelho de príncipe, uma vez que no processo formativo de um príncipe, o qual tem a função de líder, de governança, ou do nobre do século IX preconizado por Dhuoda nos moldes desse gênero literário, é preciso ter autoridade.

3 Os clássicos, segundo Calvino (1993), se constituem como os notáveis escritos de formação, que transmitem ensinamentos relevantes para qualquer momento da existência humana.

4 Compreendemos que a informação passa a ser conhecimento quando nos apropriamos dela.

5 Cumpre observar que o que entendemos por autoridade refere-se à responsabilidade do Ser mais experiente, que detém conhecimento que o permita ser consciente de seus atos e de sua função social, capaz assim de adquirir o respeito aos demais. 
Com essa perspectiva, ao lermos alguns estudos que tratam sobre a educação, especialmente, sobre o papel do mestre/docente, dois nos chamaram a atenção no que tange a forma como evidenciam a temática: $A$ violência escolar e a crise da autoridade docente, de Júlio Groppa Aquino (1998) e A crise na Educação de Hannah Arendt (1961). Além destes, outro escrito que baliza nosso estudo é do mestre medieval Boaventura de Bagnoregio, intitulado As seis asas do serafim. Os três escritos não se reportam ao gênero literário Espelho de Príncipe, como fez Dhuoda ao redigir um manual a seu primogênito, almejando uma formação do perfeito nobre cristão, mas os textos suscitam-nos a reflexão sobre a autoridade e a responsabilidade que as pessoas e, sobretudo, o professor/mestre desempenham em seu lócus de atuação e, por conseguinte, na sociedade. Afinal, a nosso ver, na ambiência educacional, são os professores que atuam como líderes, como autoridades para o bem educar de seus alunos. Contudo, os referidos textos são escritos por estudiosos de diferentes épocas, de áreas distintas do conhecimento, com fundamentações teóricas diferentes, mas que nos apontam para percepções que evidenciam a ausência do sentido de autoridade, de responsabilidade, o 'espelho' outrora visto como pertinente à formação prezada por Dhuoda.

Desse modo, procuraremos demonstrar, com este estudo, que olhar o passado nos toca enquanto vida na medida em que nos permite pensar a educação. Nesse sentido, se em Dhuoda vemos a preocupação em redigir um livro que sirva de espelho para as ações de seu filho, de sua formação, para se torne um 'perfeito nobre'; observaremos em Boaventura de Bagnoregio o destaque à formação do líder, da boa governança, dos 'degraus' necessários a serem trilhados pelo mestre para que se torne, de fato, mestre, o exemplo, o espelho aos seus estudantes.

Esclarecemos, portanto, a organização deste estudo. Após as aproximações com os textos e as questões elencadas, entrelaçaremos o contexto histórico e as formulações contidas no Manual de Dhuoda, explicitando sua proposta pedagógica, ou seja, ao ler o texto daquela que ensina, analisamos a relação educativa que ela estabelece com o filho e entendemos isso como um projeto de educação, procurando compreender em que medida sua proposta segue as premissas do gênero literário Espelho de Príncipe. 


\section{O sentido de autoridade e líder: reflexões e aproximações}

O primeiro texto, A violência escolar e a crise da autoridade docente de Aquino (1998), trata da violência e da autoridade no contexto escolar, destacando como um dos motivos para essa problemática o fato de que tanto a escola quanto seus sujeitos não se identificam como seres diretamente envolvidos no processo. Uma das razões a essa ausência de pertencimento ou reconhecimento seria a forma como eles os compreendem na escola e esta, por sua vez, como é vista por eles na sociedade:

Em termos especificamente institucionais, a ação escolar seria marcada por uma espécie de "reprodução" difusa de efeitos oriundos de outros contextos institucionais molares (a política, a economia, a família, a mídia etc.), que se fariam refletir no interior das relações escolares. [...] a escola e seus atores constitutivos, principalmente o professor, parecem tornar-se reféns de sobredeterminações que em muito lhes ultrapassam, restando-lhes apenas um misto de resignação, desconforto e, inevitavelmente, desincumbência perante os efeitos de violência no cotidiano prático, posto que a gênese do fenômeno e, por extensão, seu manejo teórico-metodológico residiriam fora, ou para além, dos muros escolares. Nessa perspectiva, a palavra de ordem passa a ser o "encaminhamento". Encaminha-se para o coordenador, para o diretor, para os pais ou responsáveis, para o psicólogo, para o policial. Numa situação-limite, isto é, na impossibilidade do encaminhamento, a decisão, não raras vezes, é o expurgo ou a exclusão velada sob a forma das "transferências" ou mesmo do "convite" à auto-retirada. Como se pode notar, os educadores quase sempre acabam padecendo de uma espécie de sentimento de "mãos atadas" quando confrontados com situações atípicas em relação ao plácido ideário pedagógico. Entretanto, o cotidiano escolar é pródigo em eventos alheios a esse ideário-padrão. (Aquino, 1998, online)

O autor destaca que a problemática que ocorre no interior da escola não é compreendida como de responsabilidade de seus 'atores constitutivos', mas sim é delegada ao sistema econômico, político, à família, aos meios de comunicações, ou seja, todos os setores sociais interferem no ambiente escolar e tem sua culpabilidade , já os professores, diretores, coordenadores, enfim, os atores da escola não sentem essa responsabilidade, afinal, a instituição escolar é fruto ou, simplesmente, o 'espelho' da crise que acomete as relações sociais. Assim, diante da omissão das pessoas envolvidas na escola, o autor assinala uma nova postura, a do 'encaminhamento', isto é, encaminha-se de uma esfera a outra na instituição, mas não há quem se responsabilize, que se comprometa com a problemática em evidência.

Nesse sentido, ao conformar-se com a situação, já que do ponto de vista desses sujeitos, a sociedade, o contexto em que estão inseridos são assim e não há o que se fazer, justificam sua inoperância e se eximem da responsabilidade concernente a cada pessoa, e, sem perceberem ou reconhecerem, perdem a autoridade, a referência, 
a direção.

No segundo texto, escrito por Hannah Arendt (1961), intitulado A crise na Educação, a autora o inicia tratando do processo de crise em que a questão da educação se deparou, no século XX, na América. A autora ressalta esta ideia evidenciando que essa crise tornou-se um problema político. Contudo, Arendt (1961, p. 2) destaca que em face das adversidades que assolam a política, a mesma não se atentou àquela não só porque "[...] é tentador considerá-la como mero fenômeno local, desligadas dos problemas mais importantes do século [...]", como também, em seu ponto de vista, é difícil pensar, de forma política, a educação.

Em virtude dessa crise, a autora considera imprescindível 'retirar' desse campo do saber preconcepções que a cerceiam e produzem preconceitos, pois do ponto de vista da autora "Uma crise só se torna desastrosa quando lhe pretendemos responder com ideias feitas, quer dizer, com preconceitos" (Arendt, 1961, p. 2). Essa 'retirada' possível passa pela conscientização dos sujeitos da educação ao fazer com que não se destituam de sua autoridade em função de uma educação democrática:

Deste modo, o que faz com que a crise da educação seja tão especialmente aguda entre nós é o temperamento político do país, o qual luta, por si próprio, por igualar ou apagar tanto quanto possível a diferença entre novos e velhos, entre dotados não dotados, enfim, entre crianças e adultos, em particular, entre alunos e professores. É óbvio que este nivelamento só pode ser efetivamente alcançado à custa da autoridade do professor e em detrimento dos estudantes mais dotados. (Arendt, 1961, p. 5)

Com o intuito de apagar o passado, erradicar a diferença entre os desiguais, os países lutam para cessarem as desigualdades sociais e hierárquicas, enfim, fazerem todos iguais. Contudo, essa postura acentua uma crise na sociedade, pois as pessoas não são, naturalmente, iguais. Do ponto de vista da autora, essa política acomete a educação, pois tende a situar professores e alunos em um mesmo patamar: o da igualdade, ainda que não o sejam; e, por conseguinte, ocasiona a quebra de autoridade do professor, dificultando ou mesmo tolhendo a aprendizagem do aluno, uma vez que ao ser igual ao professor o aluno nada tem a aprender, logo, o professor nada tem a ensinar. Assim, a autoridade, para Arendt (1961), é uma responsabilidade dos pares para com o próximo, em suma, para com a sociedade:

O professor [...] é aquele que é capaz de ensinar qualquer coisa. A formação que recebe é em ensino e não no domínio de um assunto particular. [...] Porque o professor não tem necessidade de conhecer a sua própria disciplina, acontece frequentemente que ele sabe pouco mais do que os seus alunos. O que daqui decorre é que, não somente os alunos são abandonados aos seus próprios meios, como ao professor é retirada a fonte mais legítima da sua autoridade enquanto professor. Pense-se o que se pensar, o professor é ainda aquele que sabe mais e que é mais competente. Em consequência, o professor não autoritário, aquele que, contando com a autoridade que a sua competência Ihe poderia conferir, quereria abster-se de todo o autoritarismo, deixa de poder existir. Foi 
uma moderna teoria da aprendizagem que permitiu à pedagogia e às escolas normais desempenhar este pernicioso papel na atual crise da educação. Essa teoria é, muito simplesmente, a aplicação lógica da nossa terceira ideia-base, ideia que foi durante séculos sustentada no mundo moderno e que encontrou a sua expressão conceptual sistemática no pragmatismo. Essa ideia-base é a de que se não pode saber e compreender senão aquilo que se faz por si próprio. A aplicação à educação desta ideia é tão primitiva quanto evidente: substituir, tanto quanto possível, o aprender pelo fazer. (Arendt, 1961, p. 6-7)

A partir do momento em que o professor tem de ensinar ao aluno 'saber-fazer', ou seja, entendendo o ensino somente como aquele que pode ser materializado, seu saber abstém-se de profundidade, de propriedade em um determinado tema, conteúdo . Assim, estabelece-se um 'conhecimento' pautado em informações aligeiradas, superficiais. No afã de conhecer de tudo um pouco, o professor, efetivamente, conhece muito pouco e, com isso, o conhecimento/a, ciência elaborada, consolidada no curso da história, cede lugar a um ensino, um saber transformado em pragmatismo, como bem demonstra a autora na passagem. Desse modo, o professor deixa de ser autoridade em seu lócus de atuação, afinal, ele se iguala ao seu aluno no que tange ao conhecimento. Isso, portanto, dificulta o aprendizado do aluno, posto que não lhe seja requisitado ou propiciado o uso da memória, da reflexão, aspectos imprescindíveis para a formação dos estudantes, condição elementar para o uso do intelecto, do discernimento em suas ações. Ao conhecer somente o presente, restringir-se a ele em nome do cotidiano, é como se estivesse delimitando a existência da humanidade à existência do próprio sujeito, não lhes pertencendo o passado. $A$ sensível compreensão de tempo histórico fora, outrora, observada por Bloch (2001, p. 65) ao assinalar que "[...] A incompreensão do presente nasce fatalmente da ignorância do passado. Mas talvez não seja menos vão esgotar-se em compreender o passado se nada se sabe do presente".

Nesse sentido, a pertinência do professor em se fazer instrumento de mediação entre passado e o presente está em fomentar o sentido de responsabilidade inerente e necessário à condição humana. Portanto, ensino e educação são faces de uma mesma moeda.

Os dois autores, contemporâneos, que trouxemos à baila para fundamentar nosso debate explicitaram que o conhecimento pressupõe apropriar-se de saberes elaborados cientificamente pela humanidade, no curso da história. O ensino, por sua vez, tem sua legitimidade conservada se preservar a tradição do conhecimento. E, nesse aspecto, bem demonstraram a pertinência em se preservar a autoridade do professor.

Recuando na história, e guardadas as devidas proporções, o terceiro escrito, intitulado As seis asas do Serafim, do mestre medieval do século XIII, Boaventura de Bagnoregio , também nos ensina sobre a pertinência da autoridade daquele que ensina, o mestre, 
ou aquele cuja função assenta-se na arte da governança, da perspectiva de liderança com vistas ao bem comum. A partir da leitura desta obra, observamos o quão imbuído de autoridade e sabedoria deve se apropriar um líder:

Dá ao sábio ocasião de aprender, e se lhe acrescentará sabedoria. Sendo que muitas vezes o sábio, por uma simples ocasião, consegue adquirir sabedoria mais alta, como também, não raro, se aprende pela estultícia de outrem, o presente opúsculo poderá incitar à reflexão, sobretudo os novatos e os que ainda não possuem muita prática no ofício de governo e no perfeito discernimento do bem e do mal [...] Dentre muitos devem ser escolhidos superiores os mais idôneos. Os principiantes precisam de um mestre (Boaventura, As seis asas de Serafim, Prólogo, § 1).

Tendo em vista a formação humana e intelectual de uma pessoa, sobre a qual discorremos anteriormente, destacando a importância da figura do professor enquanto autoridade, observamos, com essa passagem, que esse processo formativo também foi objeto de reflexão, sob outro contexto, de Boaventura de Bagnoregio. Do ponto de vista deste pensador medieval, é preciso que os principiantes sejam orientados por uma pessoa experiente e com sabedoria, já que se assim não o fosse, os ensinamentos não possibilitariam a capacidade em discernir entre o bem e o mal. Do mesmo modo que, se este alguém não trilhasse o conhecimento reflexivo dos princípios sagrados, seus atos não convergiriam ao bem comum, à humanidade. Sendo assim, não se constituiria em líder ou mestre, posto que para o autor seja inerente ao líder, àquele que ensinava, pensar primeiro em seu semelhante para depois em si mesmo, em sua singularidade.

Nesse sentido, o autor compreende que Jesus foi o exemplo de líder deixado pelo Criador, e por meio de seus ensinamentos sagrados evidenciou a possibilidade que Deus concedeu aos homens de tornarem-se mestres. Contudo, para alcançar tal intento, somente àqueles que desenvolvessem a inteligência recebida e, ao refletir, agissem de acordo com os mandamentos de Deus poderiam, assim, se destacar. Desse modo, adquirir o discernimento para trilhar o caminho entre o bem e o mal e, por conseguinte, chegar à salvação eterna seria conquistado apenas por meio dos ensinamentos dos mestres, os quais, por não somente ensinar, mas praticar o que se ensinava é que se consistiria em um bom líder:

Por conseguinte, é mister que aqueles que deverão governar a outros utilmente, possuam várias virtudes, das quais algumas se refiram a si mesmos, a fim de viverem irrepreensivelmente; outras se refiram aos seus superiores, para obedecerem humildemente e devidamente; e mais outras, enfim, se refiram aos súditos, de acordo com as quais deverão regê-los meritoriamente e os promoverão a aspirações mais altas. (Boaventura, As seis Asas do Serafim, cap. I, § 4)

A boa governança, tendo em vista o poder de liderança, pressupunha, também, virtudes, as quais são apontadas pelo autor em três perspectivas: as virtudes concernentes 
ao próprio homem ou o próprio líder; aquelas que se reportavam a necessidade de os discípulos compreenderem o respeito pertinente aos seus superiores; e, por fim, as que implicariam na importância de saber ordenar, e esta ordem deveria balizar os atos humanos pelos princípios da Sagrada Escritura. Desse modo, liderar significava obedecer às ordens dos líderes superiores, em que a humildade deveria fazer-se presente nesse agir humano e, por conseguinte, ensinar ou ordenar seus súditos a fundamentar suas ações nos princípios sagrados. Esses ensinamentos de liderança e humildade, também são, anteriormente, considerados por Dhuoda como pertinentes à formação de Guilherme, afinal, deve obediência e fidelidade à autoridade do rei (Carlo, o Calvo), à seu pai e à Deus, devendo diante deles agir com humildade.

Com base nessas premissas, Boaventura parte seu discurso, e refere-se aos homens da Igreja, que se destacavam como líderes. Em consonância às formulações apresentadas pelo autor, o bom governante seria aquele que sabia dirigir sua família, direcionar os filhos, ensinando-os a discernir entre o bem e o mal. A Igreja e seus representantes, por seu turno, teriam a incumbência de ensinar os mandamentos divinos e, com isso, suas ações deveriam, conscientemente, ser comedidas e suas palavras sabiamente proferidas, pois suas atitudes e condutas seriam exemplo para os pares, servindo de modelo. É, pois, sob este aspecto, o de modelo a ser seguido que observamos que Dhuoda redige o Manual dedicado ao seu primogênito Guilherme prezando, com ele, à formação do nobre perfeito cristão do século IX, ou nas palavras da autora "[...] para que sea leído como modelo de tu formación" (Dhuoda, 1995, p. 51).

\section{O Manual de Dhuoda: um Espelho de Príncipe}

Dhuoda foi uma mãe aristocrata de origem germânica e aliada à dinastia carolíngia, que escreveu o Manual, intitulado, La educación Cristiana de mi hijo, para seu filho, Guilherme. Esta é a única obra que os estudiosos de Dhuoda reconhecem como de sua autoria, e, a nosso ver, este escrito oferece-nos um duplo aprendizado: o conhecimento histórico, pois elucida o conturbado contexto do qual a autora foi partícipe, e o educativo, por se encaixar nos padrões formativos do gênero literário Espelho de Príncipe. Essa obra expressa a crise vivida pelo Império Carolíngio e o início das relações feudovassálicas. Ao redigi-lo Dhuoda procura ensinar a seu filho os valores morais, os comportamentos e as virtudes necessárias à sua educação (Nunes, 1995).

Dhuoda faz duas observações que nos remete ao gênero Espelho. Primeiramente, a menção ao jogo de dados/tabuleiro, que era indicado para que os jovens se distraíssem e, em concomitância, fossem iniciados na aprendizagem da estratégia 
e da tática militar. Segundo, a menção ao costume das mulheres de se olhar em um espelho no intuito de averiguar a limpeza de seu rosto e, também, deixá-lo bonito para seu respectivo esposo. Dhuoda deseja que Guilherme se entretenha com o Manual como fosse um espelho e um jogo de tabuleiro:

Como el juego de las tablas entre los otros juegos mundanos aparece ahora como el más conviniente y adaptado a los jóvenes, o como algunas mujeres tienen la costumbre de mirar su cara en los espejos, para limpiar los defectos y mostrar su belleza com la intención de agradar a sus maridos en esta vida, así espero que tu, atareado por las muchas ocupaciones mundanas y seculares, leas frecuentemente este pequeño libro que te he dedicado a ti, como si se tratara de un mirarse em los espejos y un juego de tablas, em recuerdo mio, y no lo desprecies. [...] Encontrarás en él todo lo que deseas aprender; también hallarás um espejo en el que podrás contemplar sin duda la salud de tu alma, de forma que puedas agradar en todo, no sólo al mundo, sino también al que te ha formado del polvo de la tierra. (Dhuoda, 1995, p. 55-56, grifos da autora)

Atenta à formação do filho, tendo em vista as condições sociais de sua época, a autora insiste para que ele leia o Manual para salvação de sua alma e de seu corpo. Este objetivo poderia ser atingido por meio da sabedoria, obtida pela apropriação dos ensinamentos contidos no Manual, e do laço jurídico, estabelecido por meio do juramento de fidelidade ao suserano.

Costa (2001) nos auxilia no entendimento do que seria o gênero literário dos Espelhos, embora trate de um período posterior ao de Dhuoda. Por meio de seu artigo, intitulado O Espelho de Reis de Frei Álvaro Pais (c. 1275-1349), e de seu conceito de tirania, podemos compreender o conceito de espelho para os medievais:

Espelho do latim speculu: reprodução fiel da imagem, representação, reflexo. Em seu sentido figurado, um modelo, exemplo a ser seguido, imitado. Deriva do verbo depoente latino speculor, cuja primeira acepção é observar. Essas palavras, por sua vez, derivam da raiz indo-europeia scop. [...] Mas como os pensadores da Idade Média entendiam esta alegoria? A tradição veterotestamentária traz a idéia do Espelho como um lugar que o homem, ou melhor, os reis, podem vislumbrar a ação de Deus. No Livro da Sabedoria, obra que se insere na tradição literária parenética [...] encontra-se uma passagem em que o autor se vale desta metáfora reino-terrestre celeste: "A Sabedoria é mais móvel que qualquer movimento [...] Ela é um aflúvio do poder de Deus, uma emanação puríssima da gloria do Onipotente, pelo que nada de impuro nela se introduz. Pois ela é um reflexo da luz eterna, um espelho nítido da atividade de Deus e uma imagem de sua bondade" (Sb, 7, 24-26). (Costa, 2001, p. 339)

O autor parte do vocábulo em latim para nos informar da acepção literal e figurada de espelho e, então, apresentar a acepção medieval. Explicando que o termo referese, primeiramente, à representação fiel de uma imagem, afirma que, no medievo, relaciona-se à Sapiência: esse objeto (espelho) é um meio/possibilidade de os homens medievais observarem a ação divina e a imagem de sua benevolência: 
Assim, desde a tradição deuterocanônica, o Espelho é o lugar da contemplação, a porta por onde os soberanos podem receber a iluminação que reflete a luz divina da Sabedoria. Com ela, através do Espelho, os reis podem exercer sabiamente o ofício da Justiça à maneira de Salomão. O Espelho representa a Sabedoria e faz parte da simbologia do poder monárquico e da educação do príncipe.

Por sua vez, na tradição filosófica ocidental, o Espelho também representa, desde Platão (c. 429-347 a.C.) até Plotino (204/205 - 270 d.C.), a alma. Segundo este último, a imagem de uma pessoa está sujeita a receber a influência de seu modelo, como um Espelho (PLOTINO, Ennéades, Paris, IV, 3); a alma possui duas faces: um lado inferior, voltado para o corpo, e um lado superior, voltado para a inteligência (PLOTINO, Ennéades, III, 43; IV, 88). [...] Platonista da escola de Orígenes, Gregório acreditava que para qualquer método ser eficaz deveria se como um Espelho. Assim como uma virgem, espécie de corpo-espelho onde as pessoas poderiam ter um vislumbre da pureza da alma, da imagem de Deus. [...] (Costa, 2001, p. 340).

Costa aborda, detalhadamente. o significado de espelho na cultura medieval. Iniciando pela tradição bíblica, passa para a tradição filosófica (mencionando Platão, Plotino e Gregório de Nissa) e esclarece que o sentido medieval dessa alegoria é o de lugar de contemplação das virtudes.

Lauand esclarece que:

O Espelho é um gênero literário que traça o retrato de um ideal, especialmente o ideal moral. Na Gália franca, os espelhos eram sobretudo obras de espiritualidade escritas por clérigos para leigos. Daí a extrema originalidade de Dhuoda, uma mulher, leiga, e mais: uma mãe escrevendo para seu filho. Original também é o caráter pessoal e autobiográfico que Dhuoda imprime ao livro, que não se reduz a um tratado de moral ou espiritualidade, mas visa a formação geral do perfeito gentlemam. (LAUAND, 1986, p. 122)

No Manual de Dhuoda, o ideal preconizado é o do perfeito nobre cristão. Sua obra não pode ser considerada apenas como de espiritualidade, justamente porque visa a formação integral de seu filho, ou seja, sua formação corpórea e espiritual, que seria pautada em diversos conhecimentos.

Merino, fundamentando-se em Hadot, afirma que obras permeadas por regras de comportamento já eram encontradas desde o inicio da Idade Média. Exemplifica com Santo Agostinho, que, no século IV, um tempo de guerras, invasões e hostilidades, redigiu dois escritos bíblicos na forma desse gênero literário: um foi direcionado aos clérigos e aos laicos e o outro, de caráter semelhante, foi destinado aos príncipes cristãos, com o intuito de formar uma cultura religiosa que conduzisse seus comportamentos.

Outro autor no qual Merino se apoia para abordar esse gênero literário é P. Toubert. Reproduzimos uma das passagens citadas por Merino, porque, nela, são descritas as 
peculiaridades desse estilo literário:

En primer lugar, la composición de la obra es relativamente libre y sólo limitada em su organización por una comparación obligatoria entre las virtudes y los vicios. En la misma obra - y constituye la segunda característica -, se preconiza un ideal social basado en una combinación de la moral cristiana y la moral establecida por los caballeros de la época. En tecer lugar, la argumentación esta toda ella imbuída del pensamiento agustiniano. Finalmente, respecto al contenido, la obra depende totalmente del público al que esta destinada. (TOUBERT apud MERINO, 1995, p. 21)

O Manual de Dhuoda contém as características mencionadas por Toubert. Durante sua leitura, podemos detectar o cotejamento entre os vícios e as virtudes, a presença de um ideal social unindo a moral cristã e a moral cavalheiresca (demonstrada pela polidez e pela gentileza, conforme ela as descreve, instando-o a praticá-las) e, sobretudo, a relação entre seus argumentos e o pensamento agostiniano.

Assim, a premissa veiculada nos Espelhos de Príncipes de que ao seguir as instruções contidas nos manuais de governança o príncipe se tornaria perfeito e, assim como ele, todo o seu reino, reflete em Santo Agostinho. Isto porque a concepção ideal de homem como base para a formação humana (enquanto realidade pertencente ao mundo terreno) segue a premissa agostiniana de que a perfeição (que remete a ação divina) deve ser fundamento da formação do homem (um ser terrestre), à medida que observamos em seu pensamento que a realidade terrestre pode ser compreendida como a réplica, relativamente, bem sucedida de um ideal, ou seja, para Santo Agostinho "[...] a imagem vista no espelho é que é de fato a imagem ideal da realidade terrestre". (Le Goff, 1999, p. 360)

Em razão do desdobramento educativo e histórico, respectivamente, contido no Manual de Dhuoda, vamos nos deter em dois aspectos que evidenciam a influência do pensamento agostiniano. O primeiro é que, em todas as partes da obra, percebemos que a autora se fundamenta na Sagrada Escritura. Suas referências mais constantes são os Salmos, livro bíblico estudado por Santo Agostinho em uma de suas obras. Por exemplo, o Salmo 41, citado por Dhuoda:

[...] Así, dice en el Salmo 41: Como el ciervo... . Los ciervos tienen esta frecuente costumbre: cuando tratan de atravesar en grupo los mares o anchos ríos de aguas com remolinos de mar, uno tras outro, apoyan la cabeza y la cornamenta sobre la espalda del anterior para sostener sus cuellos unos a otros, y así, descansando poco a poco, pueden atravesar más fácil y velozmente el rio. Tal es su inteligencia y tal es también su discreción que, cuando perciben la fadiga del primero, cambian al primero al último y eligen como primero al más cercano, para que este sostenga o reconforte a los demás. Así, reemplazándose unos a otros, se transmite por cada uno de ellos el afecto del amor [...]. (Dhuoda, 1995, p. 99) 
Esse salmo também é mencionado pelo antigo pensador.

[...] Corre a la fuente, desea a la fuente de agua. Em Dios está La fuente de vida, fuente perenne; em su luz encontraréis La luz que no se oscurece. Desea esta luz, esta fuente, esta luz que no conocen tus ojos. El ojo interior se apresta para ver esta luz, la sed interior se inflama para beber de esta fuente. Corre a la fuente, desea la fuente. Pero no corras de cualquier modo, como cualquier animal; corre como el ciervo. ¿Qué significa "corre como el ciervo"? Que no sea lento el correr; corre veloz, desea pronto la fuente. El ciervo posee uma vertiginosa velocidade. (San Agustín, 1964, p. 6)

As passagens elucidam a erudição demonstrada pela mãe ao orientar o filho a trilhar o caminho cristão. O que observamos é que a autora oferece um desdobramento educativo dos fundamentos de Santo Agostinho. Ela procura mostrar a Guilherme que ele deve ser astuto (inteligente), tal como a corça (cervo), e que deve procurar a fonte de água viva (leia-se Deus como sabedoria). Por isso, instiga-o a manter o desejo, a avidez, a sede, a estima, a honra, para que, assim, saiba amar e reconhecer a quem e por quem deseja ser reconhecido e, desse modo, possa ser recompensado com tais sentimentos.

O segundo aspecto relaciona-se ao primeiro subtítulo do capítulo II do Manual de Dhuoda:

La Trinidad santa foi um tema que santo Agostinho, teólogo e doutor da Igreja, tentou exaustivamente compreender. É com esse tema que Dhuoda inicia o capítulo. La Trinidad Santo, hijo, como leemos, se refiere al Padre, al Hijo y al Espíritu Santo. No me atrevo ni puedo decirte lo que tendría que consignarte al respecto em este capítulo de mi pequeño libro. Lee los escritos de lós Padres ortodoxos y hallarás lo que es Trinidade. (Dhuoda, 1995, p. 73)

Assim, percebemos que, como cristã, Dhuoda compreendeu a complexidade a ser enfrentada para tratar do mistério da Santíssima Trindade e aconselha Guilherme a ler os Padres da Igreja.

Ao convidar Guilherme a ler os Padres da Igreja, ela demonstra conhecer o que eles escreveram: "[...] los santos Padres tuvieron esa solícita preocupación, de forma que indagaron sobre el misterio de la Trinidad Santa, creen ló que encontraron, y lo matienen com toda seguridade" (Dhuoda, 1995, p. 73).

Dhuoda destaca-se, portanto, pelo cunho pedagógico com que estrutura sua obra e pelos princípios cristãos e morais com os quais modela seus conselhos. Em outros termos, seu Manual contém ensinamentos religiosos, mas também é revestido de um cunho educativo, destinado ao comportamento do filho e à sua convivência entre os pares. Assim, Pernoud (1984), Riché (1975) e Merino (1995) consideram esta obra o mais antigo tratado francês de Educação e o único no gênero, do período, com nítida distinção entre os demais Espelhos carolíngios: 
Dhuoda era sin duda uma de las mujeres más destacadas de su tiempo. Efectivamente, el Manual posee um enorme cúmulo de citas bíblicas, em mayor abundancia las Del Antiguo Testamento que lãs Del Nuevo, y da testimonio igualmente de lós conocimientos más extendidos em la cultura de aquella época. Contiene, por ejemplo, um pasaje de la Historia de la Natureza de Plinio el Joven, lugares de la obra de Prudencio, de Donato, etc. Es verdad que lós gramáticos de aquel entonces gustaban aducir um gran número de obras de lós autores clássicos, y por lo que el Manual nos transmite, Dhuoda debió ser uma de lãs alumnas más aplicadas em este sentido. (Merino, 1995, p. 28)

Observa-se, assim, que sua cultura estava respaldada no saber medieval que é a Sagrada Escritura e os escritos poéticos e gramáticos da antiguidade. O conhecimento de Dhuoda leva alguns estudiosos como Riché (1975) e Nunes (1995), a considerálo um saber especial e substancialmente original já que não era comum às mulheres escreverem obras dessa natureza, pois:

O Manual de Dhuoda, diz Riché, destaca-se pela originalidade, já que o seu autor não foi um clérigo mas uma mulher leiga, nobre e casada, "o que lhe confere um lugar único na literatura latina da [...] Idade Média". O Manual é um livro de educação que uma zelosa e erudita mãe escreve para seu filho, e nesse gênero é uma obra literária única, que Dhuoda redigiu como o seu testamento espiritual, sobre possuir caráter autobiográfico que os outros espelhos não apresentam [...]. (Nunes, 1995, p. 140)

Ao dialogarmos com Dhuoda, isto é, ao estudarmos seus ensinamentos, percebemos que seu conhecimento estava respaldado no pensamento cristão escolástico e que, de posse dele, ela conduziu a educação de seu filho e, por extensão, do nobre do século IX. Este anseio faz com que ela apresente uma cultura e erudição fundamentada em alguns pensadores da Antiguidade e na principal fonte moral para a época, a Bíblia. Nesse sentido, a preocupação dessa mãe cristã expressa uma questão, a nosso ver, importante: a formação humana está condicionada às ações praticadas pelos homens na terra, às suas ações cotidianas. O bem deve ser praticado em vida, em palavras, em pensamentos e, sobremaneira, em atitudes.

Guilherme não foi um príncipe, mas sua mãe procurou formá-lo nos moldes dos ensinamentos dos Espelhos, pois, assim, respeito, honra/honestidade, caridade e outras virtudes que Dhuoda aconselha seu filho a praticar seriam hábitos a serem desenvolvidos. É preciso agir de forma honesta, respeitosa e caridosa para que sejam criados nos homens os hábitos dessas virtudes.

É, pois, nessa perspectiva que compreendemos a fidelidade apresentada por Dhuoda como virtude, ou seja, Guilherme não nasceu de posse dela. Com base no Manual, consideramos que, para o período em tela, é preciso ensinar a fidelidade para que o outro aprenda a ser fiel. Desse modo, ela pode ser compreendida como virtude e, ao mesmo tempo, como um preceito educativo, pois implica um processo de ensino e de aprendizagem que a transforme em hábito e, por conseguinte, requer que a 
pessoa aja de forma intencional para que ela delineie seu comportamento. Ao se apoiar na permanência desses conhecimentos, Dhuoda procura, por um lado, educar Guilherme e, por outro, mostrar a realidade posta pela crise do Império Carolíngio e os princípios do sistema feudal.

Nesse sentido, explicitamos que a época e o texto da autora exprimem um valoroso movimento histórico. Estamos nos referindo à realidade política do Império Carolíngio. De acordo com Magne (1991), na sucessão de Carlos Magno (742-814) ascende ao trono seu único filho sobrevivente, Luís, o Piedoso (778-840). Ele foi coroado pelo próprio pai, em 813.

Luís, o Piedoso, teve três filhos do primeiro casamento: Lotário, Pepino I e Luís, o Germânico. E Carlos, o Calvo, filho da segunda união (com Judite) ocorrida após enviuvar-se. Com o nascimento deste e com a morte de Pepino I, o Imperador considera justo doar o reino a Carlos, o Calvo. Esta decisão causa revolta entre os irmãos, pois este último, por ser do segundo casamento era considerado bastardo pela tradição carolíngia. Essa situação desencadeou, em 25 de junho de 841, a trágica batalha de Fontanet (Magne, 1991). Posteriormente a esta, Luís, o Germânico e Carlos, o Calvo proclamam a junção de seus interesses. Essa aliança ficou conhecida como Juramento de Estrasburgo. Contudo, além da situação fratricida, parte do território enfrentou migrações nômades, apressando assim, o fim deste Império. É, então, nesse cenário conflituoso que Dhuoda escreve ao seu primogênito, recomendando-lhe, como nobre, ser fiel a Deus, a seu pai e ao seu rei Carlos, o Calvo:

Tienes a Carlos como señor, porque Dios, como creo, y tu padre Bernardo lo han elegido, para que tu le sirvas ya desde los primeiros años de tu juventud com todas tus fuerzas; ten en cuenta que has salido de una família elevada y noble por ambos padres; no le sirvas sólo por ser agradable a tus ojos, sino también conforme a tu inteligência, tanto mediante el cuerpo como mediante el alma; guárdale em todo acontecimiento una fidelidad provechosa, leal y segura. (Dhuoda, 1995, p. 86)

A virtude da fidelidade é apresentada por Dhuoda, de forma enfática, na terceira parte do Manual. O conteúdo desta parte revela o quanto esta mãe estava imbuída dos valores que deveriam permear a vida dos homens nobres que estavam à serviço do rei. Encontramos aqui a essência educacional de seu manuscrito, a fidelidade, evidenciada, a nosso ver, em três momentos principais, que, de fato, formam um todo: primeiramente, a fidelidade a Deus, para, no segundo momento, alcançar a fidelidade ao pai e, no terceiro, ao seu rei e senhor Carlos, o Calvo:

Te invito, pues, queridíssimo hijo Guillermo, que em primer lugar ames a Dios, como ya tienes escrito arriba; a continuación, ama, teme y honra a tu padre; recuerda que de él te viene tu condición en el mundo. Has de saber que desde os tiempos antiguos, los que amaron a los padres y les fueron sinceramente obedientes merecieron recibir por éstos la bendición divina. (Dhuoda, 1995, p. 84) 
Por prezar a formação de seu filho, a autora ensina o respeito, a honra, a leitura e a oração como quatro aprendizados indissociáveis da formação que lhe está oferecendo e que convergem para a sua integridade física e espiritual. Ela compreende que, praticando essas quatro instâncias de seu projeto de educação, o ser divino poderia conceder-lhe, além dos bens espirituais, o bem na terra. Portanto, a autoridade de Carlos, o Calvo, como líder e governante, precisa ser respeitada, honrada pelos seus pares, pelos seus súditos, dentre eles, Guilherme. É, pois sob estes aspectos, que compreendemos a pertinência de primeiramente termos refletido sobre o sentido de autoridade, liderança e governança, afinal, apesar de vários séculos nos distanciarem de Dhuoda, e esta, dos autores anteriormente analisados, os três sentidos, ainda que de forma peculiar, balizam o pensamento e ensinamentos contidos no Manual de Dhuoda.

Observamos que a preocupação da autora com a integridade física e espiritual do filho é encontrada desde o início do Manual, quando ela lhe pede que o tenha como um espelho em que possa se mirar diariamente. Assim como o espelho permite ao homem conhecer a si mesmo pelo reflexo da realidade externa, a obra dessa mãe cumpre o papel de refletir o interior dos homens e, de modo especial, de seu filho.

\section{Considerações finais}

Dhuoda destaca a importância do conhecimento para praticar a fidelidade: 0 ato de ler é um aspecto pedagógico importante em sua obra, pois seria o primeiro passo para chegar à apropriação dos ensinamentos nela contemplados. A leitura deveria fazer parte do cotidiano de Guilherme, porque Ihe daria condições de aprender todo conhecimento já propagado pelos doutores da Igreja, da Bíblia e dos demais autores que balizam a erudição de sua educadora e mãe. O caminho da leitura e da ação o auxiliaria a compreender a seriedade em cumprir com suas obrigações perante seu senhor, Carlos, o Calvo. Reitera que somente a fidelidade nas ações juntamente com a constante oração poderiam ajudá-lo a passar pelas adversidades que poderia encontrar em tempos conturbados como aqueles.

Além disso, os preceitos pela autora apresentados poderiam servir de orientação para os demais homens do período. Preceitos estes essenciais para a constituição do sujeito pensante, ou seja, daqueles cujo papel na sociedade abarca direitos e deveres, para que tenham consciência de que as ações humanas interferem no bem comum. Em suma, observamos que o Manual de Dhuoda contém o estilo do Espelho de Príncipe, mas com uma peculiaridade: ela não escreve para clérigos, laicos ou príncipes, e sim para o próprio filho.

Portanto, no decorrer de todo o Manual observamos que Dhuoda segue as premissas 
do gênero literário Espelho de Príncipe, evidenciando as virtudes necessárias para a formação humana de Guilherme. A pertinência do estudo dessa obra para a pesquisa em História da Educação remete a alguns fatores, dentre eles podemos pontuar que se constitui como recuperação de uma obra que contém um valoroso movimento histórico (o contexto político-social do Império Carolíngio), apresenta alguns fundamentos educativos do século IX e proporciona a reflexão deste fenômeno atemporal que é a Educação. Compreender como esta se constituiu ao longo da história revela a importância de experiências que estão distantes de nós, que já ocorrerem e ficaram registradas historicamente, mas que podem contribuir para a compreensão dos homens, das relações sociais e da forma como educam e são educados.

\section{Referências}

AQUINO, Júlio Groppa. A violência escolar e a crise da autoridade docente. Caderno CEDES, vol.19, n.47. Campinas: dez. 1998, p. 1-13. Disponível em: <http://www. scielo.br/scielo.php?script $=$ sci_arttext\&pid=S0101-32621998000400002>. Acesso em: 19 abr. 2016.ARENDT, Hannah. A crise na Educação (1961). Disponível em: $\quad<$ http://www.gestaoescolar.diaadia.pr.gov.br/arquivos/File/otp/hanna arendt_crise_educacao.pdf >. Acesso em: 19 abr. 2016.

BLOCH, Marc. Apologia da História ou o ofício de historiador. Rio de Janeiro: Zahar, 2001.

CALVINO, Ítalo. Porque ler clássicos? São Paulo: Companhia das Letras, 1993.

SÃO BOAVENTURA. As seis asas do Serafim. In: Obras Escolhidas. Org. L. A. DE BONI. Caxias do Sul: Livraria Sulina Editora, 1985.

COSTA, Ricardo. O Espelho de Reis de Frei Álvaro Pais (c. 1275-1349) e seu conceito de tirania. In: MALEVAL, Maria do Amparo Tavares (Org.). Atas do III Encontro Internacional de Estudos Medievais. Rio de Janeiro: Editora Ágora da Ilha, 2001, p. 338-344. Disponível em: < http://www.ricardocosta.com/artigo/oespelho-de-reis-de-frei-alvaro-pais-c-1275-1349-e-seu-conceito-de-tirania>. Acesso em: 19 abr. 2016.

DHUODA. La Educación cristiana de mi hijo. Pamplona: Editora Eunate, 1995. 
LAUAND, Luiz Jean. (Org.). Educação, teatro e matemática medievais. São Paulo: Perspectiva, 1986.

LE GOFF, Jacques. Mercadores e banqueiros da Idade Média. Lisboa: Gradiva, 1991.

MAGNE, Augusto. O mais antigo documento da Língua Francesa: ensaios sobre a parte francesa dos Juramentos de 842. Petrópolis: Vozes, 1991.

MERINO, Merino. Introdução. In: DHUODA. La Educación cristiana de m i hijo. Pamplona: Editora Eunate, 1995.

NUNES, Ruy. O dever da fidelidade no manual de Dhuoda. In: SOUZA, J. A. C. R. (Org.). O reino e o sacerdócio: o pensamento político na Alta Idade Média. Porto Alegre: EDIPUCRS, 1995.

PERNOUD, Régine. A mulher no tempo das catedrais. Lisboa: Gradiva, 1984.

RICHÉ, Pierre. Introdução. In: DHUODA. Manuel pour mon fils. Paris: Sources Chrétiennes, 1975.

SAN AGUSTÍN. Enarraciones sobre los salmos. Madrid: MCMLXIV, 1964. Disponível em: $\quad<$ http://pt.scribd.com/doc/97953175/San-Agustin-20-Narraciones-sobrelos-salmos-2>. Acesso em: 19 abr. 2016.

Recebido em maio de 2016

Aprovado em fevereiro de 2017

Terezinha Oliveira É Professora doutora do Departamento de Fundamentos da Educação e do Programa de Pós-Graduação em Educação da Universidade Estadual de Maringá. É bolsista de produtividade junto ao CNPq - PQII. Coordenadora do Grupo de Estudos Transformações Sociais e Educação nas Épocas Antiga e Medieval (GETSEAM).

Email: teleoliv@gmail.com

Ana Paula dos Santos Viana é Doutoranda em Educação pelo Programa de PósGraduação em Educação da Universidade Estadual de Maringá (UEM-PR). Bolsista pela Capes. Membro do Grupo de Estudos, certificado pe lo CNPq, Transformações Sociais e Educação nas Épocas Antiga e Medieval (GETSEAM). Email: ana_psviana@ hotmail.com 